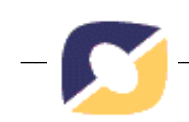

\title{
Tecnologias de Informação e Comunicação: Um Enfoque no Desenvolvimento da Criticidade na Educação Profissional
}

\author{
Cláudia Zank - PPGEDU/UFRGS - claudiazank@gmail.com \\ Patricia Alejandra Behar - PPGIE/UFRGS - pbehar@terra.com.br
}

\begin{abstract}
Resumo: A educação profissional técnica de nível médio não pode ficar restrita à preparação para o mercado de trabalho, mas também deve ter fins humanistas, estimulando a criticidade dos alunos. As Tecnologias de Informação e Comunicação podem contribuir para isso. Para tanto, é preciso que os professores tenham uma formação pedagógica no qual as tecnologias sejam aplicadas e discutidas nesta perspectiva. O artigo faz uma revisão da teoria acerca dos usos efetivos e possíveis das Tecnologias de Informação e Comunicação na educação, bem como da educação profissional e da formação pedagógica de seus docentes. O intuito é discutir os limites e possibilidades de uso das Tecnologias de Informação e Comunicação para o desenvolvimento da criticidade nos alunos da educação profissional.
\end{abstract}

Palavras chave: Educação profissional. Criticidade. Tecnologias de Informação e Comunicação.

\section{Information and Communication Technologies: A Focus on Development of Criticality in Professional Education}

Abstract: The professional education at high school level cannot be restricted to the preparation for the labor market, it also must have humanistic ends, stimulating the criticality of the students. The Information and Communication Technologies can contribute to it. Therefore it is necessary for teachers to have pedagogical training in which the technologies are applied and discussed in this perspective. The article reviews the theory of the effective and potential uses of Information and Communication Technologies in education as well as of professional education and the pedagogical training of teachers. The intention is to point out the limits and possibilities of using Information and Communication Technologies in order to stimulate the criticality of the students in professional education.

Key Words: Professional education. Criticality. Information and Communication Technologies

\section{Introdução}

Ainda que não seja igualitário o acesso às Tecnologias de Informação e Comunicação (TIC), vive-se em uma era de constantes inovações tecnológicas, na qual as informações são facilmente acessadas. Segundo Tarcia e Cabral (2012), muitas das tecnologias utilizadas são definidas e impostas pelo contexto. Trata-se, nesses casos, de uma realidade instalada em que as tecnologias são incorporadas às rotinas e hábitos sem qualquer reflexão.

A escola, como espaço social e de formação humana, poderia proporcionar esta reflexão. No entanto, conforme apontam Coll, Mauri e Onrubia (2010), os usos que os docentes fazem das TIC é limitado, relacionando-se ao trabalho pessoal (escrever, pesquisar etc). Estão distantes, portanto, da sala de aula e de um uso reflexivo por parte dos alunos. Por conseguinte, também se afastam de uma educação com fins humanistas, para a qual seria necessário estimular a criatividade e a criticidade dos alunos (FREIRE, 1971). Criticidade é aqui entendida como "apropriação crescente pelo homem de sua posição no contexto. Implica 
na sua inserção, na sua integração, na representação objetiva da realidade" (FREIRE, 1996, p. $60)$.

Proporcionar aos alunos uma educação com fins humanistas tem sido uma das discussões centrais na Educação Profissional. A preocupação é que a formação não seja voltada somente para as necessidades do mercado de trabalho, mas que também desenvolva todas as potencialidades do aluno.

Diante deste cenário, este artigo objetiva debater, a partir de uma revisão da teoria, os limites e possibilidades de uso das TIC para o desenvolvimento da criticidade nos alunos da educação profissional ${ }^{1}$. Pressupõe-se que o uso limitado e acrítico dos recursos digitas, conforme apontado por Coll, Mauri e Onrubia (2010), pode estar relacionado a uma formação pedagógica falha.

O artigo relaciona, assim, três subáreas da educação e as dispõe sobre formas de seções. A próxima seção trata da Informática na Educação e debate o uso efetivo que os docentes têm feito das TIC bem como usos que poderiam contribuir para o desenvolvimento da criticidade nos alunos. A seção 3 trata da educação profissional, discutindo a possibilidade de uma formação humana. Na sequência, a seção 4 debate a qualidade dos cursos de formação docente para a educação profissional ${ }^{2}$, observando se estão possibilitando aos professores uma formação reflexiva e crítica quanto à aplicação das tecnologias digitais em sala de aula. Após, são apresentadas as considerações finais.

\section{Usos Efetivos e Usos Possíveis das Tecnologias de Informação e Comunicação na Educação}

São inúmeros os textos que enaltecem o potencial das TIC e das mídias digitais para a educação. No entanto, segundo Coll, Mauri e Onrubia (2010, p.66), “[...] a capacidade efetiva dessas tecnologias para transformar as dinâmicas de trabalho, em escolas e processos de ensino e aprendizagem nas salas de aula, geralmente ficam muito abaixo do potencial transformador e inovador que normalmente lhes é atribuído". De acordo com estes autores, para que o potencial das TIC na educação se torne realidade é preciso levar em conta o contexto de uso dessas tecnologias. Em outras palavras, como professores e alunos estão, efetivamente, utilizando as tecnologias digitais em sala de aula e com qual objetivo.

$\mathrm{Na}$ tentativa de identificar e descrever os usos das TIC, Coll, Mauri e Onrubia (2010) propõem uma classificação a partir da qual as tecnologias estão sempre mediando relações entre partes de um "triângulo interativo" formado por professor - aluno - conteúdo. O que "define o tipo de uso que se dá às TIC é sua posição na rede de relações que se estabelecem entre os três elementos do triângulo interativo" (Idem, op. cit., p. 85). Esta classificação contempla 05 categorias nas quais as TIC são apresentadas como instrumentos:

a) Mediadores das Relações entre Alunos e Conteúdos/Tarefas de Aprendizagem;

b) Mediadores das Relações entre Professores e Conteúdos/Tarefas de Ensino e Aprendizagem;

c) Mediadores das Relações entre Professores e Alunos ou dos Alunos entre si;

d) Mediadores da Atividade Conjunta Desenvolvida por Professores e Alunos;

e) Configuradores de Ambientes ou Espaços de Trabalho e de Aprendizagem.

A fim de verificar o contexto de uso das TIC, Coll, Mauri e Onrubia (2010), realizaram um levantamento sobre seu uso pelo professorado. O levantamento aponta um uso limitado, sendo os mais frequentes aqueles relacionados à busca e acesso à informação e ao trabalho pessoal (usos "periféricos" como digitar textos; preparar aulas etc). Os usos que 
menos aparecem nestes estudos são aqueles que levam os alunos a trabalhar colaborativamente e a atuar como produtores e difusores da informação.

Assim, ao relacionar estes estudos com a classificação proposta, os autores observam que a maioria dos usos identificados no levantamento corresponde às duas primeiras categorias da classificação. Já os usos correspondentes às outras três categorias são infrequentes ou nulos. Coll, Mauri e Onrubia (2010) concluem que as TIC, "quando utilizadas, tanto pelos professores quanto pelos alunos, com frequência, é para fazer o que já se fazia sem elas: buscar informação para preparar as aulas, escrever trabalhos, fazer apresentações em sala de aula, etc" (Idem, op. cit., ,p. 87).

$\mathrm{O}$ número de pessoas que possuem acesso a computadores e internet tem aumentado significativamente nos últimos anos. Contudo, se o uso que se faz das TIC nas salas de aula permanecer como o demonstrado no levantamento realizado por Coll, Mauri e Onrubia (2010), haverá crescimento em relação ao acesso e utilização das tecnologias, mas não haverá, na mesma medida, um 'consumo' consciente das informações disponibilizadas. Tratando-se da educação especificamente, as informações não se transformarão em conhecimento e tampouco haverá reflexão acerca do potencial das tecnologias digitais para o empoderamento do cidadão e para as atitudes participativas e democráticas (KELLNER, 2004).

Para que ocorra esta conscientização, é preciso que a educação tenha um papel mais ativo no desenvolvimento da criticidade nos alunos. Neste sentido, a aplicação das tecnologias digitais em sala de aula pode contribuir. Para tanto, em vez do uso limitado mostrado no levantamento realizado por Coll, Mauri e Onrubia (2010), é preciso que as TIC sejam utilizadas com o intuito de vencer alguns desafios. Baseado em Coll e Monereo (2010) e em Monereo e Fuentes (2010), destaca-se como possíveis usos das TIC:

- Na criação de espaços de movimentos sociais diversos e como "tecnologia persuasiva" (Captology), ou seja, como tecnologias que possam influenciar os usuários para causas nobres.

- No combate à infoxicação (intoxicação informativa), contribuindo para formar alunos que saibam gerenciar as informações, utilizando-as da forma mais adequada possível.

- Na realização de atividades enriquecedoras, construtivas e criativas.

- Em ações que possibilitem "[...] dotar o usuário de um sentido crítico que supere certa aceitação acrítica e relativista que impregna a sociedade-rede" (MONEREO, FUENTES, 2010, p. 347).

Com foco em todas estas necessidades e ainda em outras, autores como Kellner (1998, 2001; 2004); De Abreu (2011) e Kellner e Share (2005, 2008) têm, baseado na pedagogia crítica de Paulo Freire, levado adiante estudos sobre alfabetização ${ }^{3}$ crítica das mídias.

Para Kellner e Share (2005), a alfabetização crítica das mídias pode tornar-se uma ferramenta para que os alunos possam se transformar em pessoas mais ativas dentro da sociedade, lutando para acabar com as injustiças e para criar um mundo melhor. Segundo De Abreu (2011), a alfabetização midiática pode contribuir para a educação nas seguintes formas:

- No estímulo do pensamento crítico (crítica é entendida aqui como a reflexão - pensamento profundo, análise e avaliação).

- Na alfabetização crítica: Os alunos saem da passividade e se tornam criadores e leitores de textos críticos, se envolvem e participam dos debates que se apresentam.

- Na criação/produção de conteúdos. 
- Na colaboração - Faz com que os alunos aprendam a trabalhar com pessoas diferentes; a fazer concessões; e "oferece uma oportunidade ou 'momento de aprendizado', no qual os alunos são alertados para a importância de encontrar um terreno comum ao utilizar o processo democrático" (DE ABREU, op. cit., p.501).

Pressupõe-se que a educação profissional seria mais voltada para fins humanistas, conforme a perspectiva de Freire (1971), se as TIC fossem aplicadas em sala de aula de forma mais reflexiva e crítica, como nos usos apontados por Coll e Monereo (2010) e Monereo e Fuentes (2010), bem como naqueles sugeridos por De Abreu (2011). Para que isso ocorresse, seria preciso que os docentes tivessem uma formação para as TIC de modo a percebê-las como instrumentos mediadores de relações e de atividades conjuntas bem como configuradores de espaços de aprendizagem e trabalho (COLL, MONEREO e ONRUBIA, 2010). A Tabela 1 mostra as relações propostas no presente estudo:

Tabela 1 - Relação entre usos possíveis das TIC para fomentação do pensamento crítico, alfabetização midiática e TIC como instrumentos mediadores e configuradores. Fonte: A autora, baseada em DE ABREU (2011), COLL, MAURI E ONRUBIA (2010), COLL e MONEREO (2010) e MONEREO e FUENTES (2010).

\begin{tabular}{|l|l|l|}
\hline Usos possíveis das TIC & Alfabetização midiática: & $\begin{array}{l}\text { Utilizando as TIC como } \\
\text { instrumentos: }\end{array}$ \\
\hline $\begin{array}{l}\text { - Para promover a justiça } \\
\text { social (Tecnologia } \\
\text { Persuasiva e espaço de } \\
\text { movimentos sociais). }\end{array}$ & $\begin{array}{l}\text { - Através do estímulo do } \\
\text { pensamento crítico; da } \\
\text { alfabetização crítica; da } \\
\text { criação/produção de } \\
\text { conteúdos e da } \\
\text { colaboração. }\end{array}$ & $\begin{array}{l}\text { - Mediadores das relaços e } \\
\text { das atividades conjuntas; } \\
\text { - Configuradores de } \\
\text { espaços de trabalho e de } \\
\text { aprendizagem. }\end{array}$ \\
\hline $\begin{array}{l}\text { - Para combater a } \\
\text { alunoxicação e formar } \\
\text { gerenciar as informações, } \\
\text { fazendo uso adequado das } \\
\text { mesmas. }\end{array}$ & $\begin{array}{l}\text { - Através do estímulo do } \\
\text { pensamento crítico e da } \\
\text { alfabetização crítica; }\end{array}$ & $\begin{array}{l}\text { - Mediadores das relações } \\
\text { entre alunos e } \\
\text { conteúdos/tarefas de } \\
\text { aprendizagem e } \\
\text { das atividades conjuntas; } \\
\text { - Configuradores de } \\
\text { espaços de trabalho e de } \\
\text { aprendizagem. }\end{array}$ \\
\hline $\begin{array}{l}\text { - Para fazer uso } \\
\text { enriquecedor, construtivo e } \\
\text { criativo das TIC. }\end{array}$ & $\begin{array}{l}\text { - Através do estímulo do } \\
\text { pensamento crítico; da } \\
\text { alfabetização crítica; da } \\
\text { criação/produção de } \\
\text { conteúdos e da } \\
\text { colaboração. }\end{array}$ & $\begin{array}{l}\text { - Mediadores das relações e } \\
\text { das atividades conjuntas; } \\
\text { - Configuradores de } \\
\text { espaços de trabalho e de } \\
\text { aprendizagem. }\end{array}$ \\
\hline $\begin{array}{l}\text { - Através do estímulo do } \\
\text { pensamento crítico; da } \\
\text { um sentido crítico. } \\
\text { colabetização crítica e da }\end{array}$ & $\begin{array}{l}\text { - Mediadores das relações e } \\
\text { das atividades conjuntas; } \\
\text { - Configuradores de } \\
\text { espaços de trabalho e de } \\
\text { aprendizagem. }\end{array}$ \\
\hline
\end{tabular}

\section{Por uma formação humana na Educação Profissional Técnica de Nível Médio}

A Educação Profissional Técnica de Nível Médio é um dos níveis da Educação Profissional e Tecnológica $^{4}$ (EPT). Em 2008, a Lei 11.741 estabeleceu sua articulação com o ensino médio 
através de cursos integrados. Desde então, se discute intensamente a possibilidade de fazer com que a educação profissional traduza uma formação humana em sua totalidade, ou seja, "integrando ciência, cultura, humanismo e tecnologia, visando ao desenvolvimento de todas as potencialidades humanas" (FRIGOTTO, CIAVATTA E RAMOS, 2005, p.10). O entendimento é que a educação profissional não pode ficar restrita à preparação para o mercado de trabalho. Também deve preparar o aluno para o exercício crítico da sua profissão e da sua condição de cidadão (FRIGOTTO, 2010).

Para Machado (2010), a integração com o ensino médio pode ser uma oportunidade para as escolas de repensar seus currículos e criar "propostas e projetos pedagógicos comprometidos com a articulação criativa das dimensões do fazer, do pensar e do sentir como base da formação de personalidades críticas e transformadoras, que promovam o despertar do olhar crítico [...]" ( 2010, p. 80).

Ainda que se concorde com Machado (2010), este artigo entende que é preciso mais do que mudanças na legislação e nos currículos para que a proposta de formação humana em sua totalidade se evidencie. Também se faz necessário uma mudança na cultura escolar, pois como afirma Simionato (2011), "a escola é um ambiente social ritualizado, onde as tradições demarcadas pelas certezas do 'sempre foi assim' são partilhadas por grande número de pessoas (professores, alunos, pais, funcionários, diferentes atores sociais...) [...]” (2011, p. 100). Acrescenta-se à cultura escolar, as culturas docentes ${ }^{5}$, as quais têm em comum a característica do individualismo, e que se referem às crenças, hábitos, saberes, experiências, regras e valores, entre outras coisas (Idem, ibidem).

As culturas, tanto docentes quanto escolar, são aspectos que escapam à legislação e ao currículo. Contudo, a formação pedagógica para a educação profissional técnica de nível médio pode ser um dos caminhos que levem a alterações nestas culturas. Para que isso ocorra, no entanto, é preciso formar docentes que entendam que a educação profissional não deve ser apenas formação para o trabalho, mas também formação de "pessoas abertas, interessadas, curiosas, críticas, solidárias e de iniciativa" (MACHADO, 2010, p. 80).

Sem mudança de perspectivas na formação docente, provavelmente a educação profissional permanecerá com sua característica tecnicista de "treinamento", ou seja, "na perspectiva estrita de adaptação aos objetivos do mercado e não aos direitos dos trabalhadores e dos objetivos sociais mais amplos" (FRIGOTTO, 2010, p. 26).

\section{Formação Docente para a Educação Profissional}

Para que os professores da educação profissional possam aplicar as tecnologias digitais de forma a contribuir para o desenvolvimento da criticidade nos alunos, eles também precisam ter uma formação no qual estas tecnologias sejam assim aplicadas e discutidas. Afinal, como aponta Freire (1986, p. 60), a criticidade "há de resultar de trabalho pedagógico crítico, apoiado em condições históricas propícias". Infelizmente, no entanto, as políticas voltadas à formação de professores sempre foram emergenciais e com "tendência histórica às improvisações" (MACHADO, 2008, p. 82).

Mesmo as reformas educacionais ocorridas no final dos anos 1990 não conseguiram alterar esta situação. A começar pela Lei de Diretrizes de Bases (LDB) que não abriu espaço para a formação de professores na educação profissional. A Tabela 2 mostra os principais documentos oficiais lançados desde então e o que estabeleceram com relação à formação docente: 
Tabela 2 - Documentos Oficiais e suas decisões quanto à formação docente para a Educação Profissional Técnica de Nível Médio

\begin{tabular}{|c|c|}
\hline Documentos Oficiais & Pontos relacionados à formação docente \\
\hline Decreto $2.208 / 97$ & $\begin{array}{l}\text { a) A docência na Educação Profissional } \\
\text { pode ser exercida por monitores e } \\
\text { instrutores. } \\
\text { b) A formação pedagógica destes } \\
\text { profissionais deve ocorrer por meio de } \\
\text { licenciaturas ou de programas especiais. }\end{array}$ \\
\hline Resolução CNE/CP n²/97 & $\begin{array}{l}\text { a) Não promove nenhuma discussão } \\
\text { acerca das licenciaturas. Detém-se aos } \\
\text { cursos especiais. } \\
\text { b) Equivale os cursos especiais às } \\
\text { licenciaturas, ainda que com carga horária } \\
\text { inferior (mínimo 540h, dentre as quais, } \\
\text { pelo menos } 300 \text { horas de prática) } \\
\text { c) Estabelece, ainda, a estruturação } \\
\text { curricular dos programas especiais, a qual } \\
\text { deveria ser articulada em três núcleos: } \\
\text { Contextual; Estrutural; Integrador. }\end{array}$ \\
\hline CNE/CEB n. ${ }^{\circ}$ 29/2001 & $\begin{array}{l}\text { Respondendo a um pedido de autorização } \\
\text { do Ministério da Saúde, por meio da } \\
\text { Fiocruz e da Escola Nacional de Saúde } \\
\text { Pública, autoriza que o curso de } \\
\text { especialização dessa escola habilite } \\
\text { professores na área da Saúde. }\end{array}$ \\
\hline Decreto $\mathrm{n}^{\circ} 5.154 / 2004$ & Revoga o Decreto 2.208/97. \\
\hline Ofício CNE/001229/2004 & $\begin{array}{l}\text { Responde a nova consulta da Escola } \\
\text { Nacional de Saúde Pública e reafirma a } \\
\text { equiparação do curso de especialização à } \\
\text { licenciatura }^{6} \text {. }\end{array}$ \\
\hline Lei $11.741 / 2008$ & $\begin{array}{l}\text { a) Altera a LDB e situa a educação } \\
\text { profissional técnica de nível médio no } \\
\text { Capítulo II da Educação Básica. Com isso, } \\
\text { o pressuposto } 7 \text { que se apresenta é que o } \\
\text { professor do ensino técnico deva ter } \\
\text { licenciatura, como os demais professores } \\
\text { da Educação Básica. }\end{array}$ \\
\hline Parecer CNE/CEB, de nº7/09 & $\begin{array}{l}\text { Novamente é dada uma resposta positiva à } \\
\text { realização de um curso de especialização } \\
\text { com fins de formação pedagógica. }\end{array}$ \\
\hline
\end{tabular}

Os documentos que constam neste Quadro mostram que, dentre as três opções formativas existentes - Licenciaturas, Cursos Especiais e Especializações, somente os cursos especiais possuem especificações próprias. Há, portanto, muitas indefinições quanto às licenciaturas e especializações. Com relação a estas últimas, discute-se, ainda, sua validade para a formação pedagógica dos professores, uma vez que a baixa carga horária desses cursos pode limitá-los ao saber fazer. Com isso, contribuindo para a perpetuação da racionalidade 
técnica na educação profissional em detrimento da formação humana, já que reflexões e intervenções críticas acerca da profissão, da prática pedagógica e das relações de trabalho podem não ocorrer.

Acrescenta-se, que a baixa carga horária desta opção formativa pode impedir o aprofundamento das questões relacionadas à aplicação das TIC na educação profissional. Da mesma forma, pode impedir o desenvolvimento da criticidade quanto à utilização destas tecnologias no contexto de trabalho e sua relação com as questões sociais, políticas e econômicas.

É necessário, portanto, uma legislação apropriada que possibilite que a Especialização com fins de formação docente tenha "características diferenciadas dos cursos de especialização correntes no país” (MOURA, 2008, p. 33). Uma das características diferenciadas seria uma maior carga horária, de modo a possibilitar ao professor "assumir outra atitude, forjada a partir de outro tipo de formação, que deva ser crítica, reflexiva e orientada pela responsabilidade social" (Idem, 2008, p. 30).

Desde modo, a formação docente para a educação profissional poderá ir além de técnicas didáticas de transmissão de conteúdos, priorizando "mais o ser humano do que, simplesmente, as relações de mercado e o fortalecimento da economia" (Idem, ibidem). Talvez possa, assim, se estabelecer uma aprendizagem crítica das TIC na formação desses professores, afinal, como questionam Gonçalves e Nunes (2006, p. 15), "Se os docentes não possuem formação adequada para trabalhar com tecnologias, como irão investir na formação dos discentes para as TIC?".

\section{Considerações Finais}

A partir do que foi exposto, o entendimento é que, enquanto os usos das Tecnologias de Informação e Comunicação ficarem restritos aos apontados por Coll, Monereo e Onrubia (2010), ou seja, limitados e acríticos, as tecnologias digitais não estarão a serviço de uma educação com fins humanistas, a qual exige o estímulo à criticidade (FREIRE, 1971).

Para que haja uma transformação no uso efetivo que os professores fazem das TIC, é preciso formá-los na perspectiva de uma educação humanista. Nesta perspectiva, as tecnologias seriam vistas como instrumentos mediadores de relações e de atividades conjuntas entre professores e alunos, e como instrumentos configuradores de espaços de trabalho e aprendizagem (COLL, MONEREO E ONRUBIA, 2010). Sem uma formação adequada, práticas calcadas na mera transmissão e reprodução de conteúdos continuarão a ser reproduzidas. Da mesma forma, os alunos continuarão a receber informações sem questionálas e, portanto, sem condições de efetuar mudanças. Como aponta Freire (1986, p. 96), "Quanto menos criticidade em nós, tanto mais ingenuamente tratamos os problemas e discutimos superficialmente os assuntos".

É preciso, portanto, que a formação docente para educação profissional tenha uma política estável e bem definida. Da mesma forma, é preciso que seus cursos tenham uma carga horária que possibilite a discussão e a reflexão acerca das possíveis contribuições das TIC para o desenvolvimento da criticidade nos alunos. Assim, poderia se garantir uma função social para a Informática na Educação dentro da formação docente, afinal como Ferguson afirma, "Não ensinar sobre as mídias é tão crítico quando não ensinar sobre a gravidade: ambas interferem em nossas vidas a cada passo que damos" (2002, p. 1).

\section{Notas de Texto \\ ${ }^{1}$ Referindo-se à Educação Profissional Técnica de Nível Médio.}


${ }^{2}$ Cada nível da Educação Profissional conta com sua própria legislação e tem exigências específicas quanto à formação do docente. Neste pré-projeto somente será tratado da Educação Profissional Técnica de Nível Médio.

${ }^{3}$ A alfabetização é vista aqui na perspectiva de Freire (1987), ou seja, aquela que possibilita uma leitura de mundo.

${ }^{4}$ Os outros dois níveis são Formação Inicial e Continuada de Trabalhadores e Educação Profissional Tecnológica de Graduação e Pós-Graduação.

5 Simionato (2011, p. 103), na verdade, propõe que se use a expressão "culturas docente" (com o substantivo "cultura" no plural e "docente" no singular) para representar a heterogeneidade existente entre o professorado.

${ }^{6}$ Esta informação consta no Projeto Básico do Curso de Formação Docente em Educação Profissional Técnica de Nível Médio na Área da Saúde, realizado pelo TecSaúde - Programa de Formação de Profissionais de Nível Técnico para a Área da Saude no Estado de São Paulo.

${ }^{7}$ Baseado na a Lei 9394/96, a qual estabelece, em seu artigo ${ }^{\circ}$ 62, a formação mínima dos professores da Educação Básica.

\section{Referências Bibliográficas}

COLL, César; MAURI, Teresa; ONRUBIA, Javier. A Incorporação das Tecnologias de Informação e Comunicação na Educação: Do projeto técnico-pedagógico às práticas de uso. In: COLL, César; MONEREO, Carles (Orgs.). Psicologia da Educação Virtual: Aprender e ensinar com as tecnologias da informação e comunicação. Porto Alegre: Artmed, 2010, p. 6696.

COLL, César; MONEREO, Carles. Educação e Aprendizagem no Século XXI: Novas ferramentas, novos cenários, novas finalidades. In: COLL, César; MONEREO, Carles (Orgs.). Psicologia da Educação Virtual: Aprender e ensinar com as tecnologias da informação e comunicação. Porto Alegre: Artmed, 2010, p. 15-46.

DE ABREU, Belinha. Literacia dos Media, Redes Sociais e Ambiente Web 2.0. In:

Congresso Nacional "Literacia, Media e Cidadania". Anais. 25-26 Março 2011, Braga, Universidade do Minho: Centro de Estudos de Comunicação e Sociedade.

FERGUSON, Robert. Media Education e o desenvolvimento de uma pedagogia apropriada. Colabor@ - Revista Digital da CVA - Ricesu. Vol. 1, No 3, Fev./2002.

http://pead.ucpel.tche.br/revistas/index.php/colabora/issue/view/4. Acesso em: nov./2011

FREIRE, Paulo. Pedagogia do Oprimido. 17 ed. Rio de Janeiro: Paz e Terra, 1987.

Educação como prática da liberdade. 17. ed. Rio de Janeiro: Paz e Terra, 1986

Papel da Educação na Humanização. Revista Paz e Terra, 9, 1971, p.123-132.

FRIGOTTO, Gaudêncio.; CIAVATTA, Maria.; RAMOS, Marize. A Gênese do Decreto n. 5.154/2004: um debate no contexto controverso da democracia restrita. In: FRIGOTTO, G.; CIAVATTA, M.; RAMOS, M. (Org.). Ensino Médio Integrado: concepções e contradições. São Paulo: Cortez, 2005, p. 21 - 56. 
FRIGOTTO, Gaudêncio. A Relação da educação profissional e tecnológica com a universalização da educação básica. In: MOLL, Jaqueline (Org.). Educação Profissional e Tecnológica no Brasil Contemporâneo: Desafios, tensões e possibilidades. Porto Alegre: Artmed, 2010, p. 25-41.

GONÇALVES, Marluce Torquato Lima; NUNES, João Batista Carvalho. Tecnologias de informação e comunicação: limites na formação e prática dos professores. In: Reunião da Associação Nacional de Pós-Graduação e Pesquisa em Educação, 29., 2006, Caxambu. Anais... Caxambu: Associação Nacional de Pós-graduação e Pesquisa em Educação (ANPEd), 2006.

KELLNER, Douglas. Multiple Literacies and Critical Pedagogy in a Multicultural Society. Educational Theory, 1998, p. 103-122.

A Globalização e os Novos Movimentos Sociais: Lições para a Teoria e a Pedagogia Críticas. In: BURBULES, Nicholas C.; TORRES, Carlos Alberto. Globalização e Educação: Perspectivas Críticas. Porto Alegre: Artmed Editora, 2004, p. 195-208.

Novas tecnologias: novas alfabetizações. (Reconstruindo a educação para o novo milênio). Revista eletrônica Outras Palavras. Vol. 1, n. 1, Set. 2001.

KELLNER, Douglas; SHARE, Jeff. Educação para a leitura crítica da mídia, democracia radical e reconstrução da educação. Revista Educação e Sociedade, Campinas, vol. 29, n. 104 - Especial, p. 687-715, out. 2008.

Toward Critical Media Literacy: Core concepts, debates, organizations, and policy. Discourse: studies in the cultural politics of education. vol. 26, n. 3, pp. 369/386, sept. 2005.

MACHADO, Lucília Regina de Souza. Formação de Professores para a Educação Profissional e Tecnológica: perspectivas históricas e desafios contemporâneos. In: MEC/INEP. (Org.). Formação de Professores para Educação Profissional e Tecnológica. $1^{\mathrm{a}}$ ed. Brasília: MEC/INEP, 2008, v. 8, p. 67-82.

Ensino médio e técnico com currículos integrados: propostas de ação didática para uma relação não fantasiosa. In: MOLL, Jaqueline (Org.). Educação Profissional e Tecnológica no Brasil Contemporâneo: Desafios, Tensões e Possibilidades. Porto Alegre: Artmed, 2010.

MOURA, Dante Henrique. A Formação de Docentes para a Educação Profissional e Tecnológica. Revista Brasileira da Educação Profissional e Tecnológica, Brasília, v.1,n.1, p. 8-22, junho 2008.

MONEREO, Carles; FUENTES, Marta. Ensino e Aprendizagem de Estratégias de Busca e Seleção de Informações em Ambientes Virtuais. In: COLL, César; MONEREO, Carles (Orgs.). Psicologia da Educação Virtual: Aprender e ensinar com as tecnologias da informação e comunicação. Porto Alegre: Artmed, 2010, p. 346-365. 
SIMIONATO, Margareth Fadanelli. A Formação do Professor do Ensino Técnico e a Cultura Docente. Tese (doutorado) - Universidade Federal do Rio Grande do Sul. Faculdade de Educação. Programa de Pós-Graduação em Educação, 2011, Porto Alegre.

TARCIA, Rita Maria Lino; CABRAL, Ana Lúcia Tinoco. O Novo Papel do Professor na EAD. In: LITTO, Frederic M.; FORMIGA,Marcos (Orgs). Educação a Distância: O Estado da Arte. Volume 2. 2.ed. São Paulo: Pearson Education do Brasil, 2012. 